\title{
Composite nanostructured solid-acid fuel-cell electrodes via electrospray deposition $\dagger$
}

\author{
Áron Varga, ${ }^{* a}$ Nicholas A. Brunelli, ${ }^{b}$ Mary W. Louie, ${ }^{b}$ Konstantinos P. Giapis ${ }^{b}$ and Sossina M. Haile ${ }^{a b}$ \\ Received 30th January 2010, Accepted 24th March 2010 \\ DOI: 10.1039/c0jm00216j
}

Stable, porous, nanostructured composite electrodes were successfully fabricated via the inexpensive and scalable method of electrospray deposition, in which a dissolved solute is deposited onto a substrate using an electric field to drive droplet migration. The desirable characteristics of high porosity and high surface area were obtained under conditions that favored complete solvent evaporation from the electrospray droplets prior to contact with the substrate. Solid acid $\left(\mathrm{CsH}_{2} \mathrm{PO}_{4}\right)$ feature sizes of $100 \mathrm{~nm}$ were obtained from electrosprayed water-methanol solutions with $10 \mathrm{~g} \mathrm{~L}^{-1}$ $\mathrm{CsH}_{2} \mathrm{PO}_{4}$ and $5 \mathrm{~g} \mathrm{~L}^{-1} \mathrm{Pt}$ catalyst particles suspended using polyvinylpyrrolidone (PVP). Alternative additives such as Pt on carbon and carbon-nanotubes (CNTs) were also successfully incorporated by this route, and in all cases the PVP could be removed from the electrode by oxygen plasma treatment without damage to the structure. In the absence of additives ( $\mathrm{Pt}, \mathrm{Pt} / \mathrm{C}$ and $\mathrm{CNTs}$ ), the feature sizes were larger, $\sim 300 \mathrm{~nm}$, and the structure morphologically unstable, with significant coarsening evident after exposure to ambient conditions for just two days. Electrochemical impedance spectroscopy under humidified hydrogen at $240{ }^{\circ} \mathrm{C}$ indicated an interfacial impedance of $\sim 1.5 \Omega \mathrm{cm}^{2}$ for the $\mathrm{Pt} / \mathrm{CsH}_{2} \mathrm{PO}_{4}$ composite electrodes with a total Pt loading of $0.3 \pm 0.2 \mathrm{mg} \mathrm{cm}^{-2}$. This result corresponds to a 30 -fold decrease in Pt loading relative to mechanically milled electrodes with comparable activity, but further increases in activity and Pt utilization are required if solid acid fuel cells are to attain widespread commercial adoption.

\section{Introduction}

Due to their high efficiency, fuel flexibility, and their compatibility with inexpensive interconnect materials, intermediate temperature fuel cells are attractive alternatives to combustion engines for the conversion of chemical to electrical energy. ${ }^{1}$ Amongst fuel cell types suitable for intermediate temperature operation $\left(100-300{ }^{\circ} \mathrm{C}\right)$ solid acid fuel cells (SAFCs) offer the unique benefit of a truly solid electrolyte, specifically, $\mathrm{CsH}_{2} \mathrm{PO}_{4}$, which, in turn, provides significant system simplifications relative to phosphoric acid or alkaline fuel cells. ${ }^{2-6}$ The power output of even the most advanced SAFCs, however, has not yet reached levels typical of conventional polymer electrolyte or solid oxide fuel cells, largely due to poor activity of the electrodes. That is, while it has been possible to limit electrolyte voltage losses in SAFCs through fabrication of thin-membrane fuel cells (with electrolyte thicknesses of $25-50 \mu \mathrm{m}^{7}$ ), it has not been possible to attain high activity electrodes or to limit $\mathrm{Pt}$ loadings to competitive levels. $^{2,8}$

Because the components in SAFC electrodes $\left(\mathrm{Pt}, \mathrm{CsH}_{2} \mathrm{PO}_{4}\right.$, and pores) can each transport only one species (electrons,

\footnotetext{
${ }^{a}$ Materials Science, California Institute of Technology, 1200 E. California Blvd, Pasadena, CA, 91125, USA. E-mail: avarga@caltech.edu; Fax: +1 626395 8868; Tel: +16263954814

${ }^{b}$ Chemical Engineering, California Institute of Technology, 1200 E. California Blvd, Pasadena, CA, 91125, USA; Fax: +1 626568 8743; Tel: +1 6263954180

$\dagger$ This paper is part of a Journal of Materials Chemistry themed issue on proton transport for fuel cells. Guest editors: Sossina Haile and Peter Pintauro.
}

protons, and gas-phase molecules, respectively), one can surmise that the electrocatalysis reaction is limited to the triple-phase boundaries at which the electrolyte, catalyst and the gas phase are in contact, and where the simultaneous and coordinated transport of electrons, ions, and gas molecules can occur. Maximization of the triple-phase boundary (TPB) per unit projected area is thus a recurring theme in composite electrode systems. ${ }^{9}$ In the case of SAFC electrodes, the possibility of attaining a high density of TPBs as implied through the use of nanoparticle Pt has not been realized because of the typically large size of the electrolyte particles. At the submicron scale, recent studies have demonstrated a monotonic increase in fuel cell power output with decreasing electrolyte particle size, ${ }^{8}$ suggesting that further reductions into the nanoscale regime would indeed create extensive triple-phase contacts and dramatically enhance electrocatalytic activity. Beyond maximizing TPBs, a composite electrode must also ensure continuous pathways for ion, electron and gas phase transport. Accordingly, the aim of the presented work is to fabricate an interconnected, porous, three-dimensional nanostructured composite. Ultimately, such a structure may provide the dual benefits of enhanced electrochemical activity and reduced Pt loading.

The fabrication methodology utilized here is the electrospray technique. Electrospray has been widely used for aerosolizing liquids. ${ }^{10}$ It relies on electrostatic forces to expel micrometre sized droplets from a charged liquid. The liquid is pumped through a capillary, and, under ideal conditions, the applied electric field causes the liquid to emerge in the shape of a cone, called the Taylor cone. ${ }^{11}$ The high electric field concentrated at the tip of the cone induces the emission of a fine spray of charged droplets. 
If the liquid is a solution of solvent and solute and sufficient evaporation occurs as the droplets are accelerated towards the grounded substrate, the resulting charge concentration induces break-up of the droplet and the ultimate deposition of submicron to nanoscale particles on the substrate. A wide range of chemical and physical parameters can be varied to tune the characteristics of the resultant structure, which can span from dense thin films to porous electrodes. ${ }^{12-14}$ These parameters include solvent concentration, solution composition (affecting solution conductivity, surface tension and viscosity), temperature, gas flow rate, and spray geometry (e.g. tip-to-substrate path length, spraying direction). Here, we demonstrate that, under the appropriate set of conditions, the electrospray method can be employed to obtain porous electrode structures for solid acid fuel cells.

\section{Experimental procedures}

\subsection{Materials}

The electrolyte material $\mathrm{CsH}_{2} \mathrm{PO}_{4}$ was prepared by precipitation from an aqueous solution of $\mathrm{Cs}_{2} \mathrm{CO}_{3}$ and $\mathrm{H}_{3} \mathrm{PO}_{4}$, and the synthesis confirmed by X-ray powder diffraction. The material was redissolved into water or a methanol-water mixture at a concentration of $10-20 \mathrm{~g} \mathrm{~L}^{-1}$ to serve as the electrospray solution. The methanol : water molar ratio was varied from $0: 1$ to $1: 1$ as a means of manipulating the solution conductivity and surface tension, parameters which can both influence the outcome of the electrospray process. ${ }^{10}$ In selected experiments various forms of $\mathrm{Pt}$ and carbon were added to the solution as a means of attaining their incorporation into the final electrode structure. These were platinum black (Alfa Aesar, Stk\# 43838, nom. $\sim 30 \mathrm{~m}^{2} \mathrm{~g}^{-1}$ ); $40 \%$ platinum on carbon black (Alfa Aesar, Stk\# 42204); and multi-walled carbon nanotubes ${ }^{15}$ (MWCNTs). The solids loadings in the solutions were $5 \mathrm{~g} \mathrm{~L}^{-1}$ for the platinum black and platinum on carbon, and $<1 \mathrm{mg} \mathrm{L}^{-1}$ for the MWCNTs. To promote the suspension of these insoluble additives polyvinylpyrrolidone (PVP; Alfa Aesar, $\left.M_{\mathrm{w}} 8000 \mathrm{u}\right)^{16}$ was added at a concentration of $20 \mathrm{~g} \mathrm{~L}^{-1}$. Deposition was performed, in most cases, on carbon paper (Toray TGP-H-120), a substrate that is suitable for subsequent fuel cell fabrication because of its high porosity, good chemical stability, and high electronic conductivity. In selected experiments, dense $\mathrm{CsH}_{2} \mathrm{PO}_{4}$ served as the substrate and, for comparative purposes, deposition on alumina was also explored. Unless stated otherwise, however, all results refer to deposition on carbon paper.

\subsection{Electrospray deposition}

The electrospray apparatus used for these experiments is shown in Fig. 1. The solution enters the deposition chamber (at a controlled flow rate between 5 and $15 \mu \mathrm{L} \mathrm{min}^{-1}$ ) via a stainless steel capillary (ID $127 \mu \mathrm{m}$, OD $1.6 \mathrm{~mm}, L 50 \mathrm{~mm}$ ). The tip of this electrospray ionization (ESI) capillary is machined to a point with a half-angle of $\sim 45^{\circ}$, less than the Taylor cone half-angle of $49.3^{\circ}$. The sharpened end of the capillary opposes a heated aluminium pedestal (OD $25.4 \mathrm{~mm}$ ), placed typically at a distance of $3 \mathrm{~cm}$, onto which the substrate is mounted. An upwards spray geometry is employed so as to prevent excess droplets of solution, which can result from instabilities in the spraying process, from

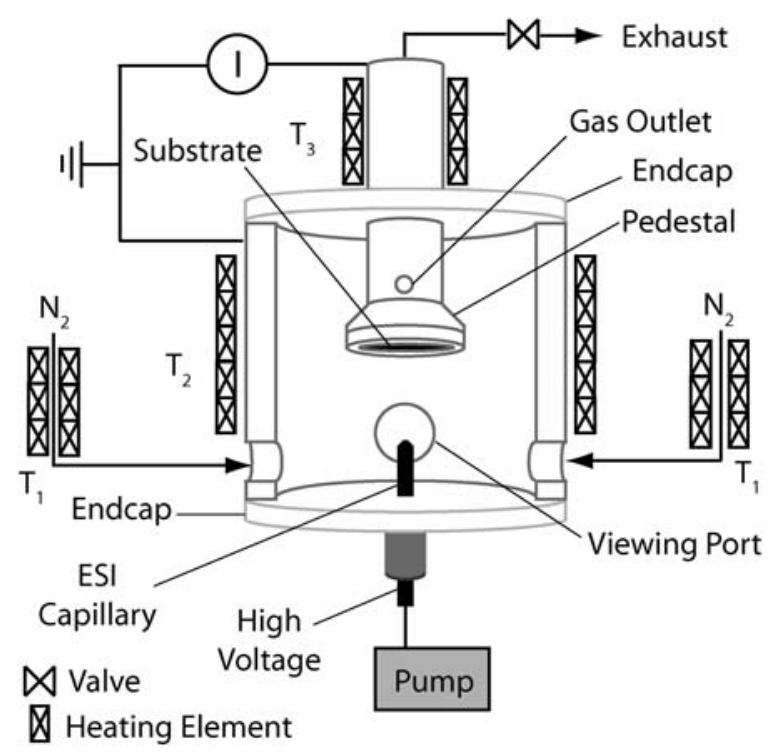

Fig. 1 Schematic of electrospray apparatus.

dripping onto the substrate. Between the capillary and the pedestal a positive bias in the 4.5 to $7.5 \mathrm{kV}$ range is applied, the precise value of which is selected in order to maintain a stable Taylor cone. The entire system is enclosed in an aluminium housing with two plastic endcaps that electrically isolate the capillary and the pedestal. (The thermal stability of the endcap material, Delrin ${ }^{\circledR}$ (polyoxymethylene) limits the upper operating temperature of the system to the plastic melting point of $175^{\circ} \mathrm{C}$.) The housing is heated independently of the pedestal. Visualization of the Taylor cone was achieved with two glass windows (dia. $\approx 12 \mathrm{~mm}$ ) placed on opposite sides of the housing. The light from one window provided sufficient contrast to observe the Taylor cone directly through the second window. Two inlet and one outlet ports in the housing accommodate flowing nitrogen, used as the drying gas. The gas is preheated to enhance the rate of solvent evaporation and was supplied at a flow rate of typically $1000 \mathrm{sccm}$ (gas space velocity of $1.8 \mathrm{~cm} \mathrm{~s}^{-1}$ ), as controlled with a mass flow controller. The current carried by the flux of charged particles to the substrate was measured using a picoammeter (Keithley 480 Digital 3.5 Digit Bench Picoammeter) connected in series between the ground wire and the pedestal. Flux measurement provides a convenient way to monitor the spraying process and the stability of the Taylor cone.

For the structures that included co-sprayed Pt-black, the Pt loading was estimated from the weight change of the sample. Because of geometric variability between different capillary tips, which have a nominal inner diameter of only $127 \mu \mathrm{m}$, fine control of the Pt deposition quantity by fixing the deposition time was not possible.

\subsection{Physical and electrochemical characterization}

Phase identification of the deposited material was performed by X-ray powder diffraction, using a Philips PW3040-Pro diffractometer $\left(\mathrm{CuK} \alpha\right.$ radiation, $2 \Theta$ range of $20^{\circ}$ to $\left.60^{\circ}\right)$. The as-prepared electrode morphology was studied by scanning 
electron microscopy using a ZEISS 1550VP Field Emission SEM.

For those experiments in which electrocatalysts were co-sprayed with the electrolyte for ultimate electrochemical characterization, the resulting structure was treated with an oxygen plasma with the objective of removing the PVP and ensuring that the sites for electrocatalysis would not be blocked by the polymer. An in-house constructed tubular plasma reactor was employed for this purpose. ${ }^{17}$ The plasma was generated by inductively coupling radio frequency $(13.56 \mathrm{MHz})$ power to an argon-oxygen gas mixture (Ar flow: $7.5 \mathrm{sccm}, \mathrm{O}_{2}$ flow: $2.5 \mathrm{sccm}$ ) with a copper coil wound around a horizontal glass chamber. The electrosprayed carbon paper substrate was placed on a pedestal $10 \mathrm{~cm}$ downstream of the excitation region and treated for 4 min using a plasma power of $150 \mathrm{~W}$ with a chamber pressure of 136 mTorr. The structures were examined by infrared spectroscopy (Nicolet 860 Magna series FTIR) before and after exposure to establish the efficacy of the oxygen plasma treatment.

Symmetric electrochemical cells were fabricated using dense $\mathrm{CsH}_{2} \mathrm{PO}_{4}$ electrolyte and two identical, electrosprayed carbon paper substrates as the electrodes. The electrolyte was obtained by cold-pressing $\mathrm{CsH}_{2} \mathrm{PO}_{4}$ powder for 20 min under a uniaxial pressure of $34 \mathrm{MPa}$. Two electrosprayed electrodes were then applied to either side of the dense electrolyte and held in place using a compression holder. The screws of the holder were tightened using a torque wrench to a fixed torque of $0.1 \mathrm{Nm}$, a value found to be sufficient for attaining good electrical contact across the electrolyte-electrode interface without inducing damage to the electrode microstructure. Two stainless steel porous discs were placed on either side of the symmetric cell in order to give uniform gas diffusion to the surface of the electrode as depicted in Fig. 2. Electrical data were collected under humidified hydrogen at $240{ }^{\circ} \mathrm{C}$ using an impedance analyzer (Eco Chemie Autolab PGSTAT302 equipped with a frequency response analysis module) operating at a voltage amplitude of 10 $\mathrm{mV}$ over frequencies ranging from $10 \mathrm{mHz}$ to $1 \mathrm{MHz}$. Hydrogen was supplied at a rate of $30 \mathrm{sccm}\left(0.6 \mathrm{~cm} \mathrm{~min}^{-1}\right)$ and humidified by flowing through a water bubbler held at $80{ }^{\circ} \mathrm{C}$.

\section{Results and discussion}

After an extensive exploration of the wide parameter space available for manipulating the outcome of the electrospray process, a highly fractal and porous structure with submicron features was ultimately obtained, an example of which is shown

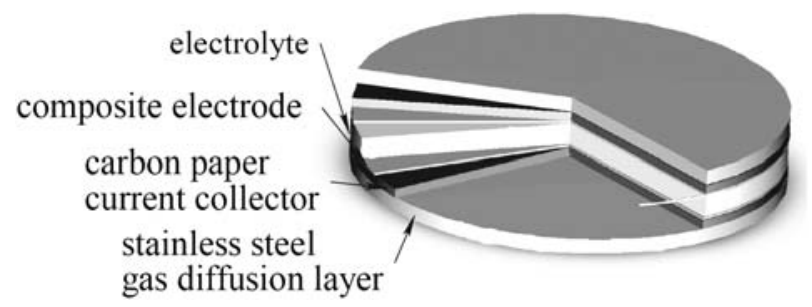

Fig. 2 Schematic of symmetric cell assembly employed for electrochemical characterization of the electrodes; composite electrodes were electrospray deposited onto carbon paper substrates.
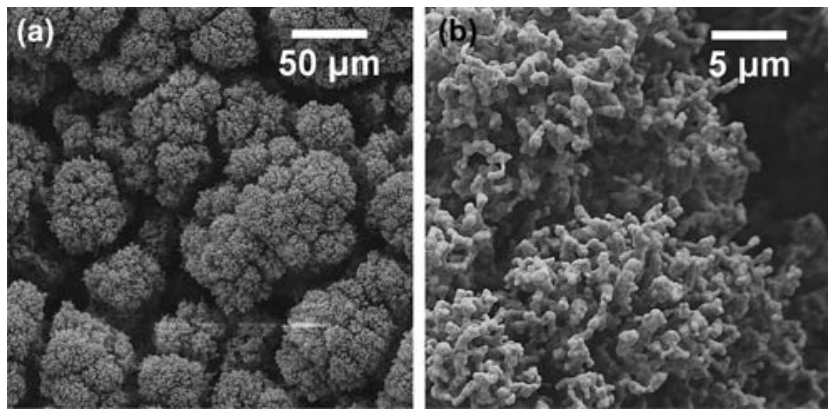

Fig. 3 SEM micrograph of porous, interconnected, three-dimensional $\mathrm{CsH}_{2} \mathrm{PO}_{4}$ structure obtained by electrospray deposition (parameters given in Table 1): (a) low magnification showing fractal conformation, and (b) high magnification showing an average feature size of $300 \mathrm{~nm}$.

Table 1 Electrospray parameters employed for the preparation of porous, nanostructured $\mathrm{CsH}_{2} \mathrm{PO}_{4}$ electrodes (e.g., Fig. 3) and solid films (e.g., Fig. 5)

\begin{tabular}{lcc}
\hline Parameter & Porous nanostructure & Thin film \\
\hline Temperature $/{ }^{\circ} \mathrm{C}$ & 140 & 90 \\
Voltage $/ \mathrm{kV}$ & 4.5 & 7.5 \\
Sheath gas flow rate $/ \mathrm{sccm}^{a}$ & 1000 & 300 \\
$\mathrm{Mol}^{a} \mathrm{methanol} \mathrm{in} \mathrm{solution}_{\mathrm{CsH}} \mathrm{PO}_{4}$ concentration $/ \mathrm{g} \mathrm{L}^{-1}$ & 50 & 0 \\
${\mathrm{Solution} \mathrm{flow} \mathrm{rate} / \mathrm{mL} \mathrm{h}^{-1}}^{a}$ & 10 & 20 \\
${ }^{a}$ Standard cubic centimetres per minute. & 1 \\
\hline
\end{tabular}

in Fig. 3. The parameters leading to this structure are summarized in Table 1 . The average feature size, as directly determined from the SEM micrograph, was found to be $c a .300 \mathrm{~nm}$. The $\mathrm{X}$-ray diffraction pattern of the nanostructure (Fig. 4) confirmed that the deposited material was $\mathrm{CsH}_{2} \mathrm{PO}_{4}$. The deposition rate of $5 \mathrm{mg} \mathrm{h}^{-1}$ and deposition efficiency (defined as the ratio of mass gain of the substrate to solute mass loss) of $50-70 \%$ were measured by weighing the sample and solution before and after deposition with a precision balance. The sample surface coverage was complete but non-uniform. The thickness of the porous film ranged from $20 \mu \mathrm{m}$ at the center of the substrate to $10 \mu \mathrm{m}$ at the

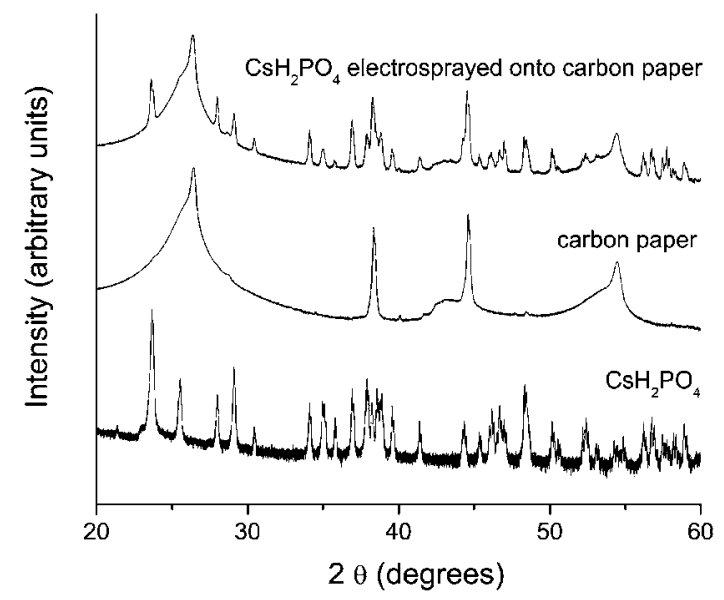

Fig. 4 X-Ray diffraction pattern of electrospray deposited $\mathrm{CsH}_{2} \mathrm{PO}_{4}$, compared to those of the carbon paper substrate and neat $\mathrm{CsH}_{2} \mathrm{PO}_{4}$. 
edge. It is thought that the non-uniform deposition ensues from the radial decrease of the electric field strength in combination with statistical variations of the charge carried by each droplet. As the dominant force acting on the charged droplets and particles is electrostatic in nature, it can be expected that their flight path follows the electric field lines and the number density of deposited particles correlates with the strength of the electric field.

Varying the substrate temperature over the range from 65 to $140{ }^{\circ} \mathrm{C}$, while holding all other parameters constant (with the exception of voltage), produced no significant change in the morphology of the nanostructure. This result provides strong evidence that the solvent completely evaporates before $\mathrm{CsH}_{2} \mathrm{PO}_{4}$ particles are deposited. Otherwise, differing amounts of residual solvent would generate differing morphologies. The absence of solvent at the final point of particle-substrate impact, in turn, suggests that the fractal nanostructure is created as a result of preferential deposition of particles onto protrusions created by growth instabilities and at which electric field effects are presumably magnified. Retention of the structure additionally suggests limited surface diffusion that could otherwise smooth the film over the course of the deposition. The alternative possibility, of void generation due to vigorous evaporation of the solvent upon contact of droplets with the substrate, is inconsistent with the temperature-independent morphology.

Overall, the preliminary evidence suggests that ensuring complete solvent evaporation is essential for obtaining fractal structures. Conditions with low solvent evaporation rates (i.e. reducing the nitrogen flow rate, eliminating methanol from the electrospray solution, and/or lowering the chamber temperature) led to the growth of a dense film, as shown in Fig. 5. While not pursued in this work, the high density of this film suggests that the electrospray method can be used for both electrolyte and electrode fabrication in fuel cell construction, as has begun to be explored for solid oxide fuel cells. ${ }^{18}$ Furthermore, exploratory depositions on $\mathrm{CsH}_{2} \mathrm{PO}_{4}$ were quite successful. This was evident, for example, from the flux monitoring during deposition: on both carbon paper and $\mathrm{CsH}_{2} \mathrm{PO}_{4}$ the electrical current was $0.6 \pm 0.1$ $\mu \mathrm{A}$ as measured over a $3 \mathrm{~h}$ period, whereas on alumina, no current was detected. Typically, electrospray deposition is not

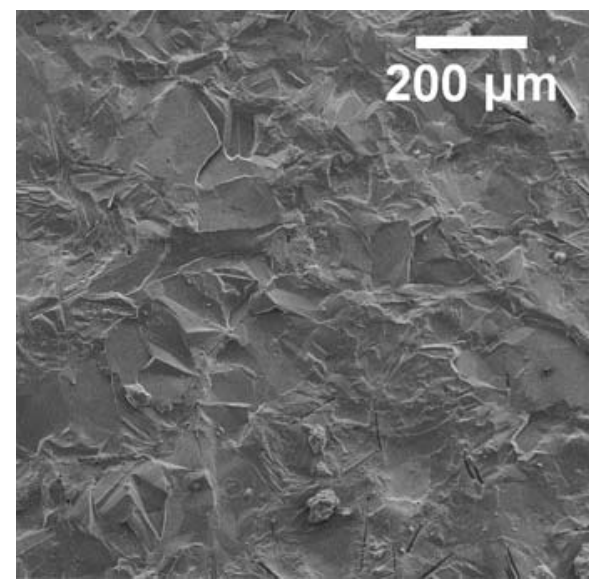

Fig. 5 SEM micrograph of dense thin film of $\mathrm{CsH}_{2} \mathrm{PO}_{4}$ obtained by electrospray deposition (parameters given in Table 1). possible on electronically insulating substrates because charge accumulation eventually deflects incoming, like-charged particles. Successful deposition here on $\mathrm{CsH}_{2} \mathrm{PO}_{4}$ suggests that the high protonic conductivity of this electrolyte (even at temperatures below the phase transition) is sufficient to permit charge dissipation. The result opens up alternative avenues for fuel cell fabrication.

Returning to the morphological features of the material deposited on carbon, Fig. 3, it is apparent that the fractal structure displays a highly attractive morphology for electrode application with high porosity and high surface area. However, the configuration was found to be unstable over time. Coalescence of the particles was evident after just two days of exposure to ambient conditions and, after seven days, the loss of surface area and porosity was severe, Fig. 6. This behavior is believed to be connected to the hydrophilic nature of $\mathrm{CsH}_{2} \mathrm{PO}_{4}$ and its capacity (though the material is not seriously deliquescent) to absorb water from the atmosphere. Similar coarsening behavior has impeded progress in the incorporation of nanoparticle $\mathrm{CsH}_{2} \mathrm{PO}_{4}$ obtained by aerosol methods into advanced SAFC electrodes. ${ }^{8}$ Furthermore, even if it were to be morphologically stabilized, the structure of Fig. 3 would require introduction of an electronically conducting phase and electrocatalysts in order to function electrochemically.

Incorporation of the electron-conducting and catalytic additives, Pt black, Pt on carbon, and MWCNTs, into the electrospray solution (while maintaining all other parameters as in Table 1) led, respectively, to the structures shown in Fig. 7-9. Two characteristics in these composite structures are distinctly different from those of the neat $\mathrm{CsH}_{2} \mathrm{PO}_{4}$ structures. First, the feature size is substantially reduced, from $\sim 300 \mathrm{~nm}$ to $\sim 100 \mathrm{~nm}$, whether the added component is Pt black, Pt on carbon, or MWCNTs. Second, the structure is markedly smoother on a $10 \mu \mathrm{m}$ scale, suggesting rapid discharge of the electrical current through the high conductivity additives. It is also noteworthy that the additive phase is not visible in the image, suggesting that the $\mathrm{Pt}$ and $\mathrm{C}$ are well dispersed. That the conducting phases can indeed be incorporated into the structures was confirmed by simple visual inspection: on black carbon paper neat $\mathrm{CsH}_{2} \mathrm{PO}_{4}$ forms a visibly white layer, whereas on a white substrate (dense $\mathrm{CsH}_{2} \mathrm{PO}_{4}$ ) the electrosprayed composite forms a visibly black, non-reflective layer.

The FTIR spectra of composite electrodes, Fig. 10, reveal a sharp difference between the as-deposited structures and those
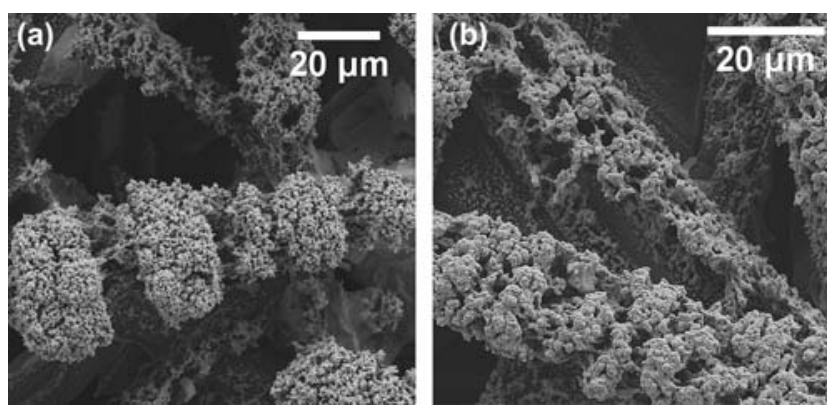

Fig. 6 SEM micrographs showing agglomeration of $\mathrm{CsH}_{2} \mathrm{PO}_{4}$ nanostructure after (a) two days and (b) seven days of exposure to ambient conditions. 

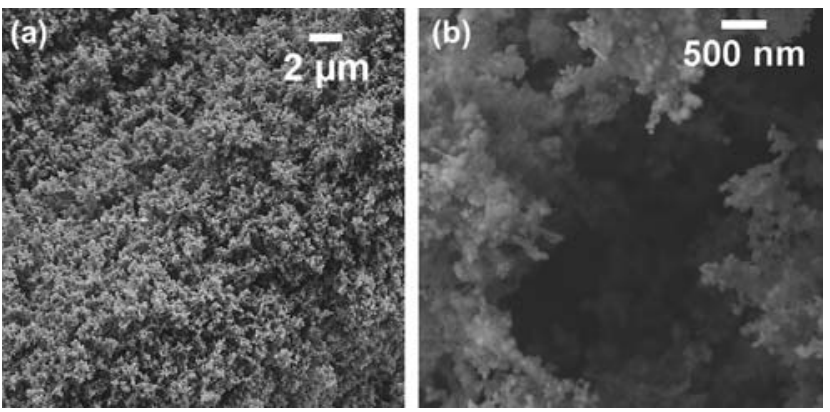

Fig. 7 SEM micrographs of composite electrode nanostructures comprised of $\mathrm{CsH}_{2} \mathrm{PO}_{4}$, Pt-black and PVP: (a) low magnification and (b) high magnification.
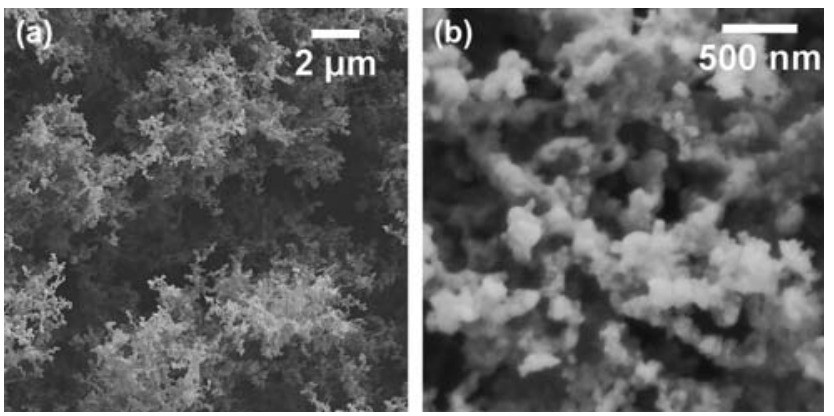

Fig. 8 SEM micrographs of composite electrode nanostructures comprised of $\mathrm{CsH}_{2} \mathrm{PO}_{4}$, Pt on carbon, and PVP: (a) low magnification and (b) high magnification.
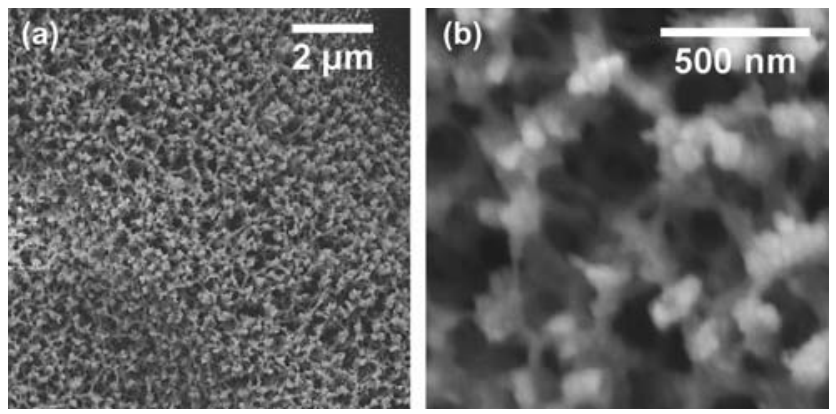

Fig. 9 SEM micrographs of composite electrode nanostructures comprised of $\mathrm{CsH}_{2} \mathrm{PO}_{4}$, multi-walled carbon nanotubes, and PVP: (a) low magnification and (b) high magnification.

exposed to an oxygen plasma treatment. The as-deposited material, prepared using Pt black as the additive, displays several IR absorption bands in the region 1000 to $4000 \mathrm{~cm}^{-1}$ which correspond to either the blank carbon paper or the reference spectrum for PVP. ${ }^{19}$ After 4 min of exposure to plasma treatment, the bands at $\sim 1650$ and $1285 \mathrm{~cm}^{-1}$ due to PVP are completely removed and the spectrum is essentially identical to that of the substrate. Rather remarkably, the structure is not only morphologically unchanged by the plasma treatment, but also morphologically stable over long periods of time subsequent to the treatment. Even after several days of exposure to ambient conditions, the plasma-treated composite structure retains its $100 \mathrm{~nm}$ feature size, Fig. 11. Thus, insoluble catalyst components can be readily incorporated into electrosprayed $\mathrm{CsH}_{2} \mathrm{PO}_{4}$

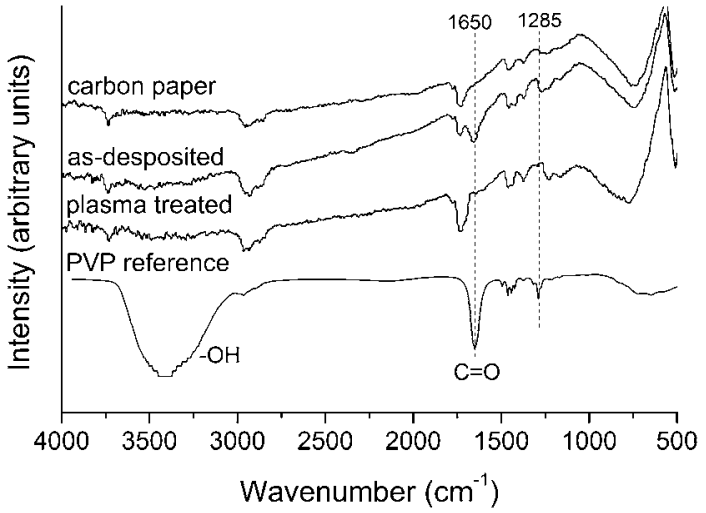

Fig. 10 FTIR spectra of (i) blank carbon substrate; (ii) as-deposited composite electrode comprised of $\mathrm{CsH}_{2} \mathrm{PO}_{4}$, $\mathrm{Pt}$ and PVP; (iii) composite electrode after oxygen plasma treatment; and (iv) reference PVP (in $\mathrm{KBr}) .{ }^{19}$ Large, broad absorption band at $\sim 3400 \mathrm{~cm}^{-1}$ apparently due to residual water.
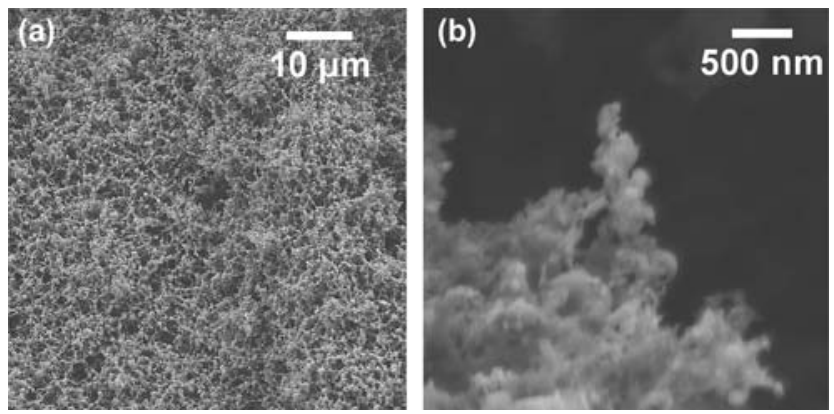

Fig. 11 SEM micrographs of composite electrode nanostructures, comprised of $\mathrm{CsH}_{2} \mathrm{PO}_{4}$, Pt-black and PVP, after exposure to ambient conditions for five days subsequent to oxygen plasma treatment: (a) low magnification and (b) high magnification.

electrodes, with the fortuitous consequence of providing morphological stability.

Electrochemical measurements were performed using electrosprayed electrodes that incorporated Pt black and had been subjected to oxygen plasma treatment for PVP removal. The effectiveness of the PVP removal was always confirmed by FTIR spectroscopy prior to electrical characterization. Based on the change in substrate mass upon electrode deposition, the $\mathrm{Pt}$ loading (mass of Pt per unit projected area) is estimated at $0.3 \pm$ $0.2 \mathrm{mg} \mathrm{cm}^{-2}$. In general, the impedance spectra, as presented in Nyquist form, Fig. 12 and 13, were found to display two overlapping arcs in the frequency regime of $1 \mathrm{MHz}$ to $10 \mathrm{~Hz}$, both attributed to the electrode behavior, as well as an offset along the real axis, corresponding to the resistance of the electrolyte. The characteristic frequencies of the observed arcs are $\sim 3 \mathrm{kHz}$, consistent with electrode behavior. Impedance spectra collected from three different samples, Fig. 12, demonstrate the high reproducibility of the method. Furthermore, the electrosprayed electrodes display excellent stability, Fig. 13. Over the course of a $24 \mathrm{~h}$ measurement under humidified hydrogen at $240{ }^{\circ} \mathrm{C}$, the electrochemical activity increased slightly in the first $12 \mathrm{~h}$ and then reached an apparently stable value. This observation suggests that coarsening of the electrode structure is minimal on 


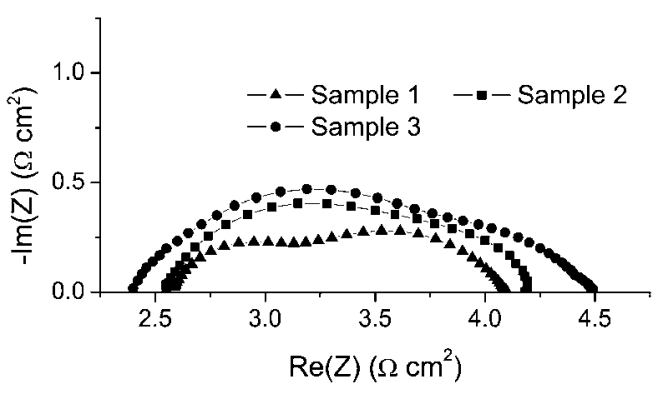

Fig. 12 Impedance spectra of representative $\mathrm{CsH}_{2} \mathrm{PO}_{4}+$ $\mathrm{Pt}\left|\mathrm{CsH}_{2} \mathrm{PO}_{4}\right| \mathrm{CsH}_{2} \mathrm{PO}_{4}+\mathrm{Pt}$ symmetric, electrochemical cells with electrosprayed electrodes on carbon and a Pt loading of $0.3 \pm 0.2 \mathrm{mg} \mathrm{cm}^{-2}$; data collected under humidified hydrogen with $p \mathrm{H}_{2} \mathrm{O}=0.4$ atm at $240{ }^{\circ} \mathrm{C}$.

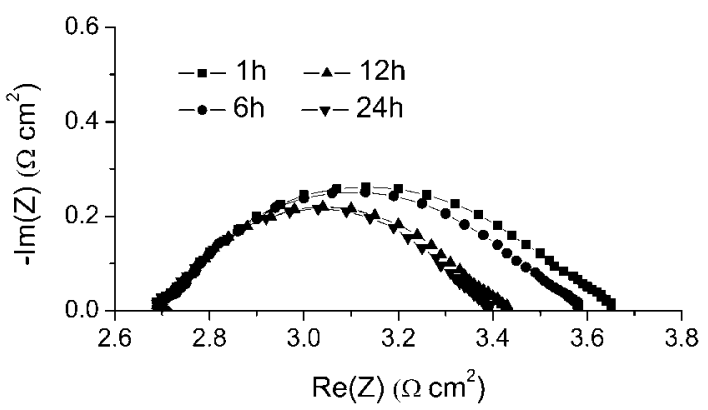

Fig. 13 Impedance spectra of a representative $\mathrm{CsH}_{2} \mathrm{PO}_{4}+$ $\mathrm{Pt}\left|\mathrm{CsH}_{2} \mathrm{PO}_{4}\right| \mathrm{CsH}_{2} \mathrm{PO}_{4}+\mathrm{Pt}$ symmetric electrochemical cell with electrosprayed electrodes on carbon and a Pt loading of $0.3 \pm 0.2 \mathrm{mg} \mathrm{cm}^{-2}$; data collected under humidified hydrogen with $p \mathrm{H}_{2} \mathrm{O}=0.4 \mathrm{~atm}$ at $240^{\circ} \mathrm{C}$ over a time period of $24 \mathrm{~h}$.

the timescale of hours, whereas interfacial contacts may improve under the slight pressure of the cell holder.

Rather significantly, the total electrode impedance measured here, of $\sim 1.5 \Omega \mathrm{cm}^{2}$ (determined simply from the total span of the electrode arcs along the real axis), is comparable to that obtained previously $\left(1.67 \Omega \mathrm{cm}^{2}\right)$ using mechanically milled electrodes of almost identical overall composition (approximately $2: 1$ by mass of $\mathrm{CsH}_{2} \mathrm{PO}_{4}: \mathrm{Pt}$ ), but with much higher total mass and hence much higher Pt loading $\left(\sim 10 \mathrm{mg} \mathrm{cm}^{-2}\right){ }^{20}$ The 30 -fold reduction in $\mathrm{Pt}$ loading without loss in activity is a highly attractive outcome of the electrospray process. Unlike the electrodes fabricated here, however, state-of-the-art SAFC electrodes incorporate $\mathrm{Pt}$ on carbon $(\mathrm{Pt} / \mathrm{C})$ and graphite in addition to Pt black and display interfacial impedance values of only $\sim 0.06 \Omega \mathrm{cm}^{2}$ under humidified hydrogen (with a Pt loading of $\left.7.7 \mathrm{mg} \mathrm{cm}{ }^{-2}\right){ }^{2}$ Efforts are presently under way to produce comparable multi-component SAFC electrodes by the electrospray process and achieve an analogous 30 -fold reduction in $\mathrm{Pt}$ loading without loss in activity. Such an outcome would render the anode performance of SAFCs comparable to state-of-the-art polymer electrolyte membrane fuel cells and set the stage for addressing the even more challenging problems of cathode electrochemical activity, stability and Pt loading. ${ }^{8}$

Finally, it is noteworthy that composite electrodes from which PVP had not been removed by an oxygen plasma treatment displayed electrochemical impedances that were only slightly higher (by about a factor of two) than those for which PVP removal had been confirmed by IR spectroscopy. This result suggests that the spraying process leaves regions of the $\mathrm{Pt}$ particles uncoated by the polymer, or that PVP is sufficiently permeable that the catalyst particles remain accessible for electrochemical reactions. The alternative possibility, that the polymer removal under the oxygen plasma treatment is incomplete, is considered less likely; FTIR spectra of the redissolved electrodes did not show any sign of the presence of organic components.

\section{Conclusions}

The viability of electrospray deposition as a solid acid fuel cell electrode fabrication tool has been demonstrated. A threedimensional, porous, interconnected $\mathrm{CsH}_{2} \mathrm{PO}_{4}$ and $\mathrm{Pt}$ nanostructure has been created with an average feature size of $100 \mathrm{~nm}$. The structure is morphologically stable under oxygen plasma treatment applied to remove the stabilizing polymer PVP, and upon exposure to high humidity at elevated temperatures. Such electrosprayed electrodes have an interfacial impedance of $1.5 \Omega$ $\mathrm{cm}^{2}$ for hydrogen electro-oxidation with a platinum loading of $0.3 \mathrm{mg} \mathrm{cm}^{-2}$. In comparison to mechanically milled electrodes of Pt black and $\mathrm{CsH}_{2} \mathrm{PO}_{4}$ with similar composition, the electrochemical activity is maintained despite an approximately 30 -fold reduction in Pt loading. While this result indicates that electrospray deposition can dramatically increase $\mathrm{Pt}$ utilization in SAFC electrodes relative to cruder fabrication methods, the specific combination of activity and Pt loading reported here is not sufficient for widespread adoption of solid acid fuel cells. However, several avenues for optimization of the resulting electrodes and their electrochemical activity are available (compositional tuning, introduction of carbon, further reducing feature size) and may ultimately enable high activity electrodes with sufficiently low precious metals content.

\section{Acknowledgements}

Funding for this project was provided by the Gordon and Betty Moore Foundation through the Caltech Center for Sustainable Energy Research, and by the Airforce Research Office, through a the subaward from Superprotonic, Inc. Additional support was provided by the National Science Foundation through the Caltech Center for the Science and Engineering of Materials, a Materials Research Science and Engineering Center (DMR052056). The authors thank Dr Chi Ma and Prof. George Rossman for assistance, respectively, with scanning electron microscopy and Infrared Spectroscopy.

\section{Notes and references}

1 J. Larminie and A. Dicks, Fuel Cell Systems Explained, John Wiley \& Sons, Chichester, England, 2003.

2 S. M. Haile, C. R. I. Chisolm, K. A. Sasaki, D. A. Boysen and T. Uda, Faraday Discuss., 2007, 134, 17-39.

3 T. Norby, Nature, 2001, 410, 877-878.

4 S. Yoshimi, T. Matsui, R. Kikuchi and K. Eguchi, J. Power Sources, 2008, 179, 497-503.

5 A. S. Bondarenko, W. Zhou and H. J. M. Bouwmeester, J. Power Sources, 2009, 194, 843-846.

6 J. Otomo, T. Tamaki, S. Nishida, S. Wang, M. Ogura, T. Kobayashi, C. J. Wen, H. Nagamoto and H. Takahashi, J. Appl. Electrochem., $2005,35,865-870$. 
7 T. Uda and S. M. Haile, Electrochem. Solid-State Lett., 2005, 8, A245-A246.

8 C. R. I. Chisolm, D. A. Boysen, A. B. Papandrew, S. Zecevic, S. Y. Cha, K. A. Sasaki, Á. Varga, K. P. Giapis and S. M. Haile, Electrochem. Soc. Interface, 2009, 3, 53-59.

9 S. Sunde, J. Electroceram., 2000, 5(2), 153-182.

10 A. G. Bailey, Electrospraying of Liquids, Wiley, New York, 1988.

11 G. Taylor, Proc. R. Soc. London, Ser. A, 1964, 280, 383-397.

12 D. Perednis and L. J. Gauckler, J. Electroceram., 2005, 14, 103-111.

13 I. Taniguchi, R. C. Van Landschoot and J. Schoonman, Solid State Ionics, 2003, 160, 271-279.

14 R. Benitez, J. Soler and L. Daza, J. Power Sources, 2005, 151, 108113.
15 The MWCNTs were synthesized by the arc discharge method and were provided courtesy of Prof. C. P. Collier.

16 C. W. Chen, D. Tano and M. Akashi, J. Colloid Interface Sci., 2000, 225, 349-358.

17 Y. Narui, D. M. Ceres, J. Chen, K. P. Giapis and C. P. Collier, J. Phys. Chem. C, 2009, 113, 6815-6820.

18 D. Marinha, C. Rossignol and E. Djurado, J. Solid State Chem., 2009, 182, 1742-1748.

19 SDBS, http://riodb01.ibase.aist.go.jp/sdbs/, National Institute of Advanced Industrial Science and Technology, accessed January 15, 2010.

20 K. A. Sasaki, Y. Hao and S. M. Haile, Phys. Chem. Chem. Phys., 2009, 11, 8349-8357. 